\title{
Declines in swimming performance with age: a longitudinal study of Masters swimming champions
}

This article was published in the following Dove Press journal:

Open Access Journal of Sports Medicine

II March 2013

Number of times this article has been viewed

\author{
Robert T Rubin ${ }^{1,2}$ \\ Sonia $\operatorname{Lin}^{3}$ \\ Amy Curtis ${ }^{4}$ \\ Daniel Auerbach ${ }^{5}$ \\ Charlene Win ${ }^{6}$ \\ 'Department of Psychiatry and \\ Biobehavioral Sciences, David Geffen \\ School of Medicine, UCLA, Los \\ Angeles, CA, USA; ${ }^{2}$ UCLA Bruin \\ Masters Swim Club, Los Angeles, \\ CA, USA; ${ }^{3}$ Saint Louis University \\ School of Medicine, Saint Louis, MO, \\ USA; ${ }^{4}$ Indiana University School \\ of Medicine, Indianapolis, IN, USA; \\ ${ }^{5}$ University of California, Berkeley, CA, \\ USA; 'oyola Marymount University, \\ Los Angeles, CA, USA
}

Correspondence: Robert T Rubin Department of Psychiatry, VA Greater Los Angeles Healthcare System, Bldg 500 Room 6428, I I30I Wilshire

Blvd, Los Angeles, CA 90073-1003, USA

Tel + I 3102683319

Fax + I 3102684377

Email robert.rubin@va.gov
Introduction: Because of its many participants and thorough records, competitive Masters swimming offers a rich data source for determining the rate of physical decline associated with aging in physically fit individuals. The decline in performance among national champion swimmers, both men and women and in short and long swims, is linear, at about $0.6 \%$ per year up to age 70-75, after which it accelerates in quadratic fashion. These conclusions are based primarily on cross-sectional studies, and little is known about individual performance declines with aging. Herein we present performance profiles of 19 male and 26 female national and international champion Masters swimmers, ages 25 to 96 years, participating in competitions for an average of 23 years.

Methods and results: Swimmers' longitudinal data were compared with the fastest times of world record holders across ages 35-100 years by two regression methods. Neither method proved to accurately model this data set: compared with the rates of decline estimated from the world record data, which represent the best recorded times at given ages, there was bias toward shallower rates of performance decline in the longitudinal data, likely owing to a practice effect in some swimmers as they began their Masters programs. In swimmers' later years, once maximum performance had been achieved, individual profiles followed the decline represented in the world records, and a few swimmers became the world record holders. In some instances, the individual profiles indicated performance better than the world record data; these swimmers achieved their times after the world record data were collected in 2005-2006.

Conclusion: Declining physiological functional capacity occurs with advancing age, and this is reflected in the performance decrements of aging Masters swimmers. Individual swimmers show different performance trajectories with aging, declines being mitigated by practice, which improves both physiological capacity and swimming technique, particularly in the early years of participation. The longitudinal data of this study indicate that individuals can participate in high-intensity swimming over several decades, competitively improving over those decades until, in some instances, they become world record holders for their age groups.

Keywords: physiological functional capacity, geriatric health

\section{Introduction}

With the recent dramatic increase in the world's aging population, research aimed at predicting and limiting the mental and physical toll of aging becomes increasingly important. Because of its large numbers and thorough records, the Masters program and the world's population of competitive Masters athletes offer a rich source of data for determining the rate of physical decline associated with aging in physically fit men and women. When compared on peak performance, competitive athletes generally decline at a rate similar to that of the general population, although they start from a 
baseline of better physical ability. ${ }^{1}$ The use of elite athletes to predict decrements in physical performance due to aging is advantageous in that their activity levels are reasonably constant and their training regimens usually are designed to limit adverse events, such as sports injuries.

Started in the late 1960 s to encourage both ex-competitive swimmers and beginning swimmers to maintain physical wellbeing and prevent cardiovascular disease, ${ }^{2,3}$ Masters swimming is a relatively low-impact, low-resistance sport, particularly suitable for the elderly. A 40-year review of studies on aging in Masters swimmers revealed that the age-related decline in performance among national champions, both men and women and in short and long swims, is linear, at approximately $0.6 \%$ per year up to age 70-75. ${ }^{3}$ Beyond age 70-75, the age-related decline accelerates in quadratic fashion in both men and women, with greater variability than in younger age groups. Of note, these conclusions were based almost exclusively on cross-sectional studies. ${ }^{3-5}$ The only published longitudinal study to date showed results similar to those of the crosssectional studies but was limited by individual swimmers' data, which spanned a median of only about 4 years. ${ }^{6}$

Several regression methods have been used to estimate the rate of decline of sporting performance with aging. To estimate age-related declines in swimming performance, Fair ${ }^{7}$ examined Masters world records of swimmers between ages 35 and 100 by regression analysis, based on the assumption of a linear percentage decline up to a transition age and a quadratic decline thereafter, the coefficients for which were estimated. Each age record was mainly held by a different person, although in some cases the same person held more than one record. Of importance, Fair ${ }^{7}$ included only nondominated data, ie, the observation at each age was a best time, not superceded by a better time at a later age. This provided the best possible age-related swim times, based on the data available at the time of analysis (2005-2006 world records).

Because the one published longitudinal study of swimming performance decrements with age covered a median time of only 4 years, ${ }^{6}$ the present study was designed to examine individual swimmers' data across longer time spans and to determine whether Fair's regression method, ${ }^{7}$ and ordinary least squares regression as a comparison, could be applied to these longitudinal data. Swimmers in the present study participated for an average of 23 years in competition.

\section{Methods}

\section{Subjects}

Longitudinal national and international data for 19 male and 26 female Masters swimming champions were obtained from US Masters Swimming ${ }^{8}$ and the International Masters Swimming Hall of Fame (IMSHOF), part of the International Swimming Hall of Fame. ${ }^{9}$ Eligibility criteria for induction into IMSHOF includes a minimum age of 25 years, participation in a minimum of 16 years of Masters swimming competitions spanning at least four 5-year age groups, recognition of swimming accomplishments, and total dominance in an age group. Included in the data were world records, top-five world rankings, top-five US rankings, and several international top-ten record holders meeting the same longevity criteria for IMSHOF membership but not yet inducted.

All records were screened for adequate longitudinal data for freestyle events. Duplicate entries in the world records, top-five world rankings, and top-five US rankings were eliminated. Freestyle events were selected, because they attract the largest number of competitors, provide the most data points, and have undergone few rule and technical changes over the years. Only long-course (50-meter pool) freestyle data were used, given the close correlation with performance in short-course (25-meter pool) freestyle events. Distances included 50, 100, and 1500 meters, the first two being sprint events and the third being an endurance event. Because the data are public records available from the Internet, Institutional Review Board permission for analysis was determined by the facility research administration not to be required.

Figure 1 provides individual swimmers' ages at which they began and ended competition. The youngest and oldest competing ages were 29 and 96 years for the men and 25 and 92 years for the women. The mean number of years of participation in competitions was 23.9 (range $=13-36$ years) for the men and 23.1 (range $=11-36$ years) for the women. Based on earlier analyses of Masters Swimming data, ${ }^{10}$ performance decline was assumed to have begun no earlier than age 35; observations for three of the men and three of the women prior to age 35 therefore were not used in the data analyses.

\section{Statistical analysis}

We applied both the regression method used by Fair ${ }^{7,11}$ in his analyses of performances in track and field, road running, swimming, and chess, and ordinary least squares regression to analyze these longitudinal data. To reflect each swimmer's best age-related performance and to eliminate year-to-year variability, as with Fair's analyses, only nondominated times were included; ie, any times for a given event that were bested by times when the swimmer was older were excluded. All times included for a given event and swimmer therefore 


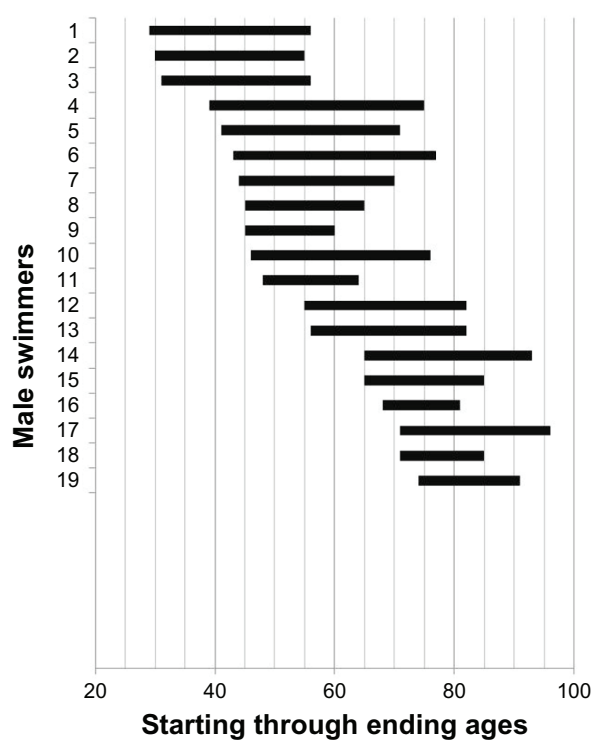

Figure I Starting through ending ages for elite Masters swimmers.

only increased with age. About half the recorded times in both the longitudinal and the Fair data sets were dominated and omitted.

Fair's method also forces all estimated errors (the difference between a swimmer's actual time and his or her estimated biological minimum time) to be positive, the rationale being that a swimmer should be either at his or her predicted biological minimum or above it, and estimated errors thus should be zero or positive. As well, Fair's method forces the estimated error at the starting age for each individual to be zero. In contrast, ordinary least squares regression does not impose these constraints.

In the present study, there are multiple observations for each swimmer, and the ages covered by the longitudinal observations vary across subjects (Figure 1). One possible method of analysis would have been to estimate separate regression coefficients for each person, in which each person for each event would have his or her own linear decline rate, transition age, quadratic decline rate, and intercept term. Given the inclusion criterion of only nondominated times, however, there would have been a very small number of intrasubject observations for the estimates. Therefore, to maximize the number of data points per regression, the subjects were pooled within each sex for each event.

\section{Results}

Contrary to our expectation, neither Fair's regression method nor ordinary least squares regression proved to be useful for this data set. Table 1 indicates these comparisons for the men's and women's 50-meter and 100-meter events.

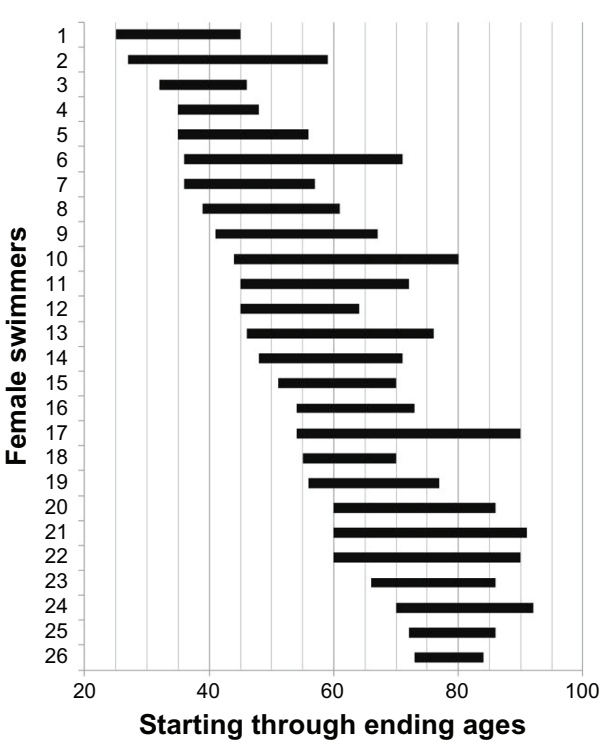

For the men in this study, the transition ages from a linear to a quadratic decline were similar, for both the Fair and ordinary least squares regression methods, compared with the Fair 2007 world record data. The 10 -year percentage rates of decline, however, were greater than those for the world record data at the younger ages but considerably less at the older ages ( $80-100$ years).

For the women, the transition ages for the longitudinal data were more than two decades older than the transition ages for the world record data, similar to the transition ages for the men and consistent with other studies using least squares regression methods on cross-sectional data. ${ }^{3}$ In contrast to the men, the women's 10-year percentage rates of decline were less than those for the world record data at the younger ages and tended to be greater at the older ages. Because statistical modeling of the longitudinal data thus proved to be unreliable, the increases in individual swimmers' times with age will be presented graphically against a background of the world record data, in order to highlight individual trajectories in performance and to illustrate one possible explanation for the unreliability of the regression analyses.

Figures 2 and 3 present data for male and female swimmers, respectively, participating in the 50-meter long course event, along with Fair's ${ }^{7}$ world record data, for ages 35-100 years. Gaps in the data across years represent omission of dominated times; as mentioned previously, approximately half the data were dominated. Logarithms of times are graphed, to reflect percent decrements with age. Of note, there are both male and female swimmers whose times are above the world records at younger ages but whose times 
Table I Analyses of men's and women's 50-meter and 100-meter long-course freestyle events, by regression method of Fair ${ }^{7}$ and by ordinary least squares regression (OLS), compared with Fair's 2007 world record data

\begin{tabular}{|c|c|c|c|c|c|c|c|c|c|}
\hline \multirow[t]{3}{*}{ Event } & \multirow{3}{*}{$\begin{array}{l}\text { No of } \\
\text { observations }\end{array}$} & \multirow{3}{*}{$\begin{array}{l}\text { Max age } \\
\text { (years) }\end{array}$} & \multirow{3}{*}{$\begin{array}{l}\text { Transition } \\
\text { age (years) }\end{array}$} & \multicolumn{6}{|c|}{ I0-year rates of decline (\%) } \\
\hline & & & & \multicolumn{6}{|c|}{ End age } \\
\hline & & & & 50 & 60 & 70 & 80 & 90 & 100 \\
\hline Men $50 \mathrm{M}$ & 87 & 96 & 76.8 & 4.5 & 4.5 & 4.5 & 5.3 & 18.6 & 38.5 \\
\hline \multicolumn{10}{|c|}{ This study (Fair method) } \\
\hline Men $50 \mathrm{M}$ & 87 & 96 & 75.8 & 3.8 & 3.8 & 3.8 & 5.3 & 20.8 & 42.4 \\
\hline \multicolumn{10}{|l|}{ This study (OLS) } \\
\hline Men $50 \mathrm{M}$ & 26 & 100 & 76.6 & 2.0 & 1.9 & 2.9 & 4.6 & 46.0 & 124 \\
\hline \multicolumn{10}{|l|}{ Fair $^{7}(2007)^{a}$} \\
\hline Men $100 \mathrm{M}$ & 89 & 96 & 73.7 & 4.6 & 4.6 & 4.6 & 8.5 & 28.7 & 54.6 \\
\hline \multicolumn{10}{|c|}{ This study (Fair method) } \\
\hline Men $100 \mathrm{M}$ & 89 & 96 & 72.2 & 3.9 & 3.9 & 3.9 & 9.1 & 27.5 & 49.6 \\
\hline \multicolumn{10}{|l|}{ This study (OLS) } \\
\hline Men $100 \mathrm{M}$ & 34 & 100 & 73.7 & 5.9 & 4.6 & 4.4 & 12.7 & 51.1 & 111 \\
\hline \multicolumn{10}{|l|}{ Fair $^{7}(2007)^{\mathrm{a}}$} \\
\hline Women $50 \mathrm{M}$ & 85 & 91 & 67.9 & 3.2 & 3.2 & 3.6 & 14.1 & 31.4 & 51.3 \\
\hline \multicolumn{10}{|c|}{ This study (Fair method) } \\
\hline Women $50 \mathrm{M}$ & 85 & 91 & 69.0 & 3.6 & 3.6 & 3.7 & 14.0 & 33.7 & 56.8 \\
\hline \multicolumn{10}{|l|}{ This study (OLS) } \\
\hline Women $50 \mathrm{M}$ & 35 & 92 & 43.9 & 2.0 & 8.7 & 15.2 & 21.7 & 30.6 & 38.0 \\
\hline \multicolumn{10}{|l|}{ Fair $^{7}(2007)^{\mathrm{a}}$} \\
\hline Women $100 \mathrm{M}$ & 114 & 92 & 70.3 & 4.2 & 4.2 & 4.2 & 11.2 & 27.6 & 46.5 \\
\hline \multicolumn{10}{|c|}{ This study (Fair method) } \\
\hline Women $100 \mathrm{M}$ & 114 & 92 & 74.5 & 4.2 & 4.2 & 4.2 & 7.7 & 31.7 & 64.7 \\
\hline \multicolumn{10}{|l|}{ This study (OLS) } \\
\hline Women $100 \mathrm{M}$ & 29 & 94 & 47.3 & 4.9 & 9.3 & 16.2 & 23.5 & 30.4 & 39.3 \\
\hline Fair $^{7}(2007)^{\mathrm{a}}$ & & & & & & & & & \\
\hline
\end{tabular}

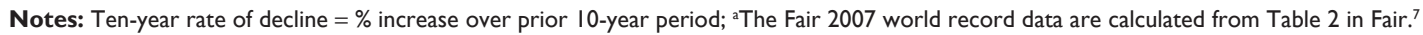

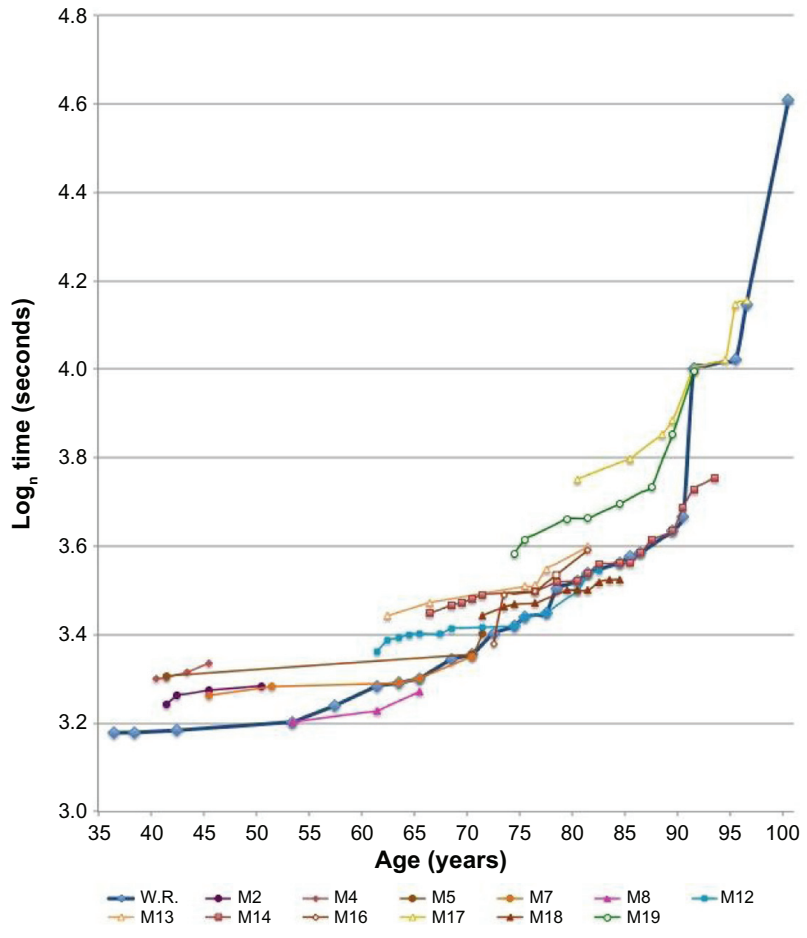

Figure 2 Men's 50-meter event - individual swimmers versus world record times.

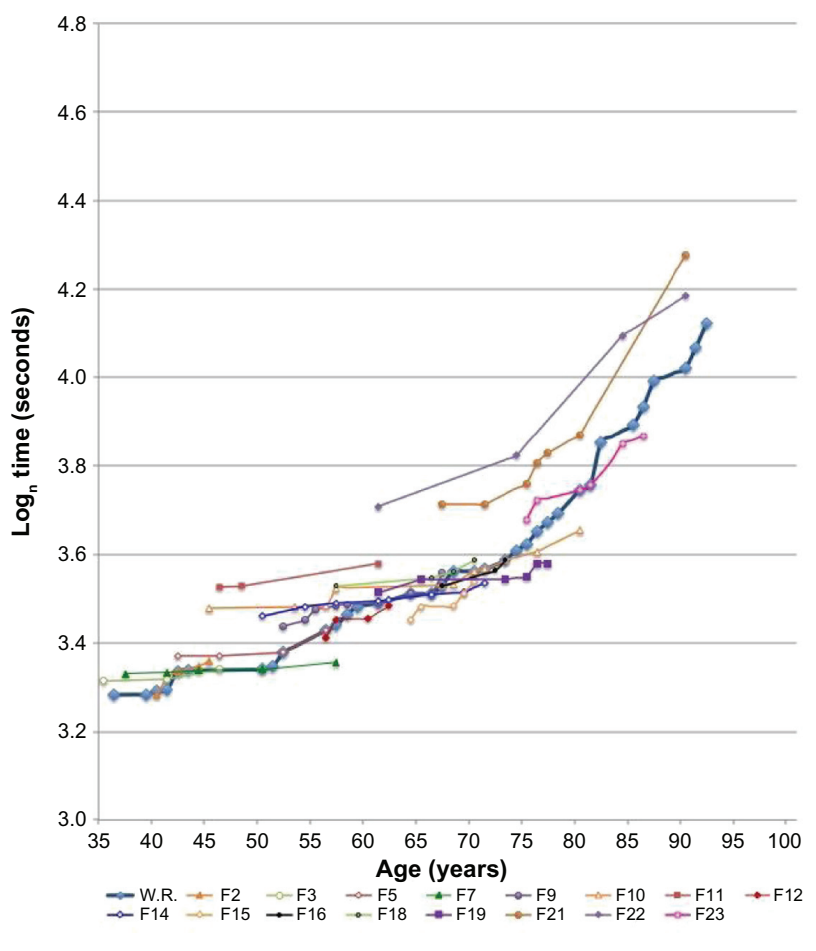

Figure 3 Women's 50-meter event - individual swimmers versus world record times. 


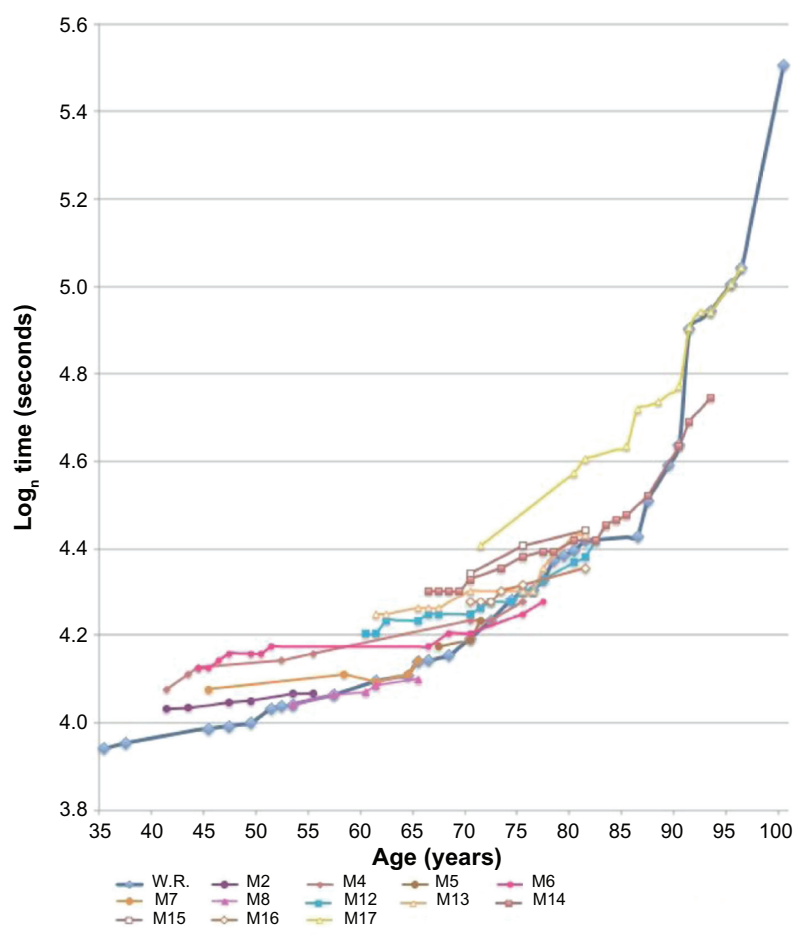

Figure 4 Men's 100-meter event - individual swimmers versus world record times.

converge with the world records as they get older (sometimes they became the world record holders). Linear performance decrements therefore were calculated from the starting ages of the individual swimmers up to the transition age, for each event, representing the linear portion of the decline in performance with age. For the 50-meter event, six of the seven men had linear performance decrements $(0.34 \%-0.55 \%$ per year) less than that for the male world record data $(0.57 \%$ per year), and ten of the 13 women had linear performance decrements $(0.13 \%-0.93 \%)$ less than that for the female world record data $(0.95 \%)$.

Figures 4 and 5 present data for male and female swimmers, respectively, participating in the 100 -meter event, and Figures 6 and 7 present similar data for the 1500-meter event. The identification of individual swimmers is consistent across all the Figures, and several are represented in more than one event. Again, there is an apparent practice effect in the years when swimmers began participating in Masters competitions, and several world records were set after the Fair data were collected. For the 100-meter event, five of the six men had linear (starting age to transition age) performance decrements $(0.26 \%-0.68 \%$ per year $)$ that were less than that for the world record data $(0.72 \%$ per year), and twelve of the 13 women had linear performance decrements $(0.10 \%-1.2 \%)$ less than that for the world record data (1.23\%). For the 1500 meter event, five of the seven men had linear performance

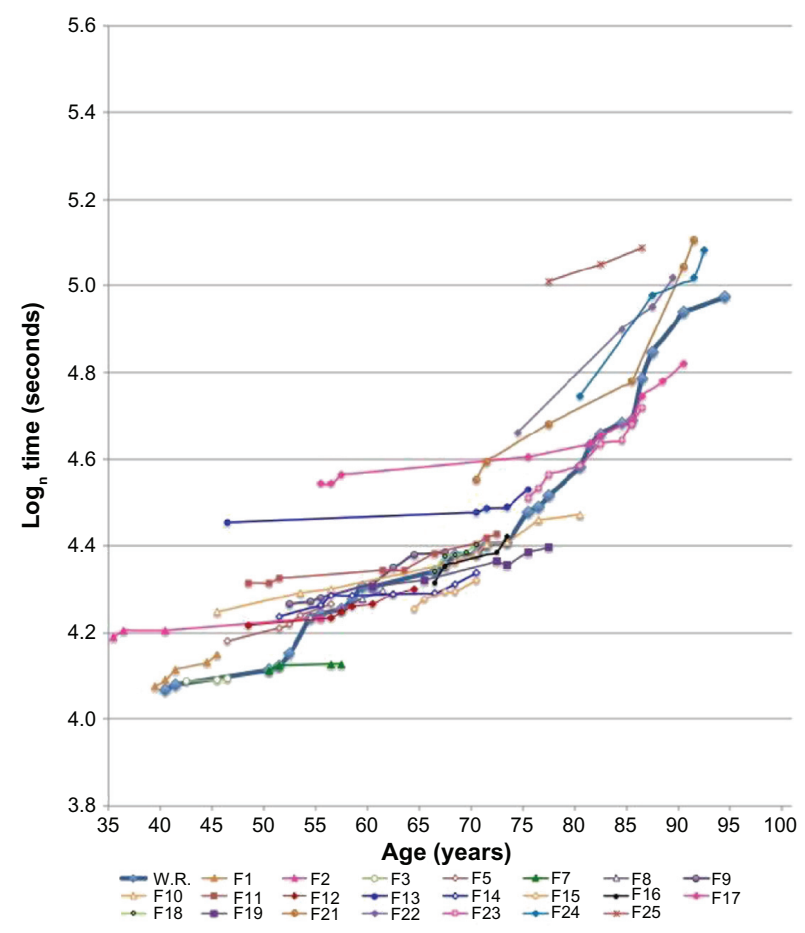

Figure 5 Women's 100-meter event - individual swimmers versus world record times.

decrements $(0.13 \%-0.55 \%$ per year $)$ less than that for the world record data $(0.69 \%$ per year), and all nine women had linear performance decrements $(0.04 \%-0.94 \%)$ less than that for the world record data (1.44\%).

As well, in all six events there were both male and female swimmers whose times were faster than the world record data. Fair $^{7}$ used world records up to 2005-2006; the swimmers in the present study whose times were faster accomplished their times after the Fair data were collected.

Finally, it should be noted that the data above age 80-85 are sparse, in that there have been relatively few swimmers in the oldest age groups to date. The sparse data above age 80-85 are exemplified in Figure 4 by the time at age 100; this represents the only male swimmer who had ever competed in the 100-meter long course event at this age.

\section{Discussion}

A key characteristic of advancing age is a decline in physiological functional capacity, resulting in reduced performance in various tasks and a concomitant increase in morbidity and mortality. ${ }^{12,13} \mathrm{~A}$ useful method for assessing the effects of age on physiological functional capacity is to determine decrements in exercise performance with aging, in elite athletes. ${ }^{10}$ Studying elite athletes rather than sedentary subjects allows for a model relatively free of confounding factors, such as variations in physical ability and disease. ${ }^{6,14,15}$ 


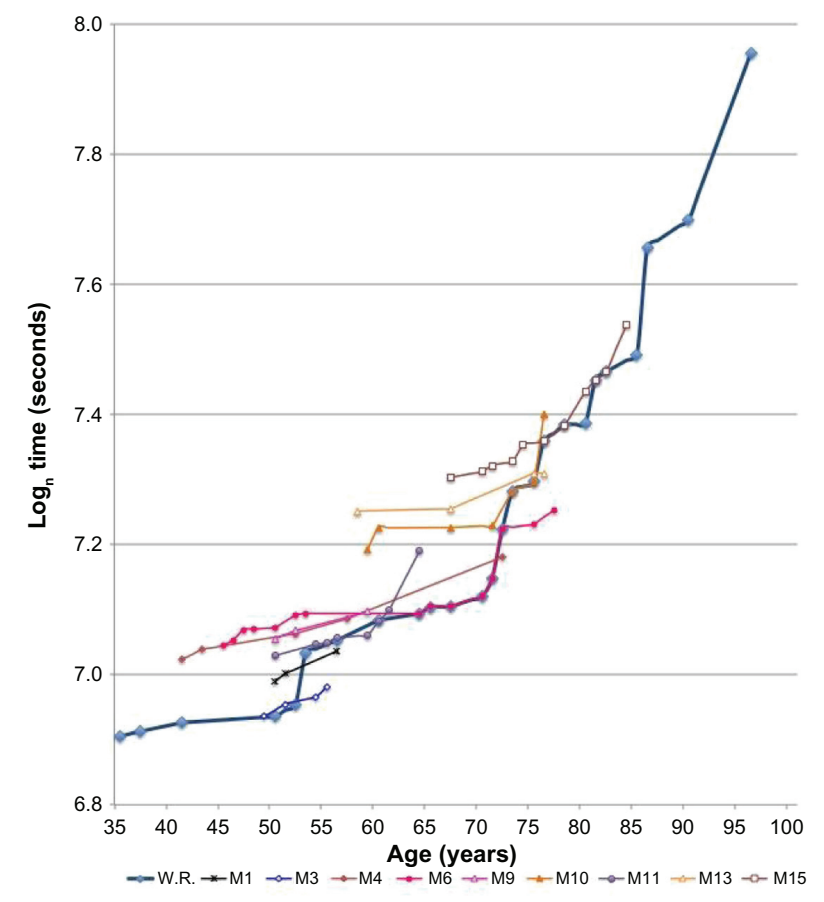

Figure 6 Men's 1500-meter event - individual swimmers versus world record times.

Swimming as an exercise of choice is advantageous for several reasons. It is a non-weight-bearing activity, permitting the study of a large array of participants, including very elderly individuals and those who otherwise might be limited by orthopedic strains and injuries. ${ }^{3}$ The roughly equal distribution of male to female participants may allow for analysis of sex differences. ${ }^{8,16}$ We exploited these aspects of Masters swimming by using the records of elite swimmers who participated for an average of 23 years. This appears to be the first presentation of swimming data covering an extensive time span.

Although not amenable to analysis by Fair's method ${ }^{7}$ or by ordinary least squares regression, the longitudinal data presented herein illustrate several aspects of changing performance with age in elite swimmers. First, for all three distances, men's average times were faster than women's average times at most ages, consistent with other performance data for a number of sports. Second, for all three distances, there was an apparent practice effect - many male and female swimmers improved their ability during their early years of participation, ${ }^{17}$ as shown by progression toward world record times as they got older. This practice effect resulted in shallower rates of linear performance decline (up to the transition age) than for the world record data, giving the appearance of better performance in these swimmers than the world record data would support and invalidating the regression analyses.

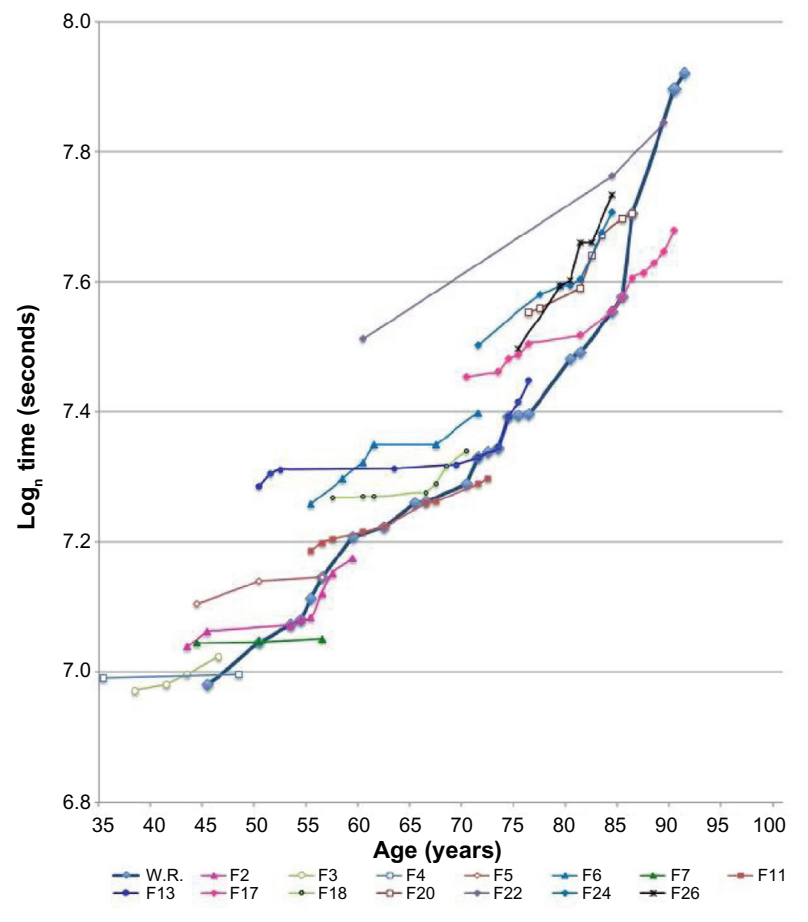

Figure 7 Women's 1500-meter event - individual swimmers versus world record times.

Third, these data are in contrast to the suggestion that longitudinal data for track athletes, ${ }^{18}$ and perhaps for elite cyclists, ${ }^{19}$ show slightly greater declines with age than do comparable cross-sectional data. Pollock et a ${ }^{18}$ reported that track athletes who maintained high- or moderate-intensity training over 20 years (ages 50 to 70 years) had similar or slightly accelerated (at age 70) declines in maximal $\mathrm{O}_{2}$ uptake than did endurance athletes of the same age in a cross-sectional study. Whether or not the slight difference was statistically significant is not indicated. For all three longitudinal data sets (track, cycling, and ours in swimming), it is not known when the participants began their training vs when their performances were measured, so they cannot be directly compared.

Some swimmers bettered the world records, particularly at older ages where the 2005-2006 world record data were sparse and not likely representative of biological minimums. For example, male swimmer M14, if included in the 50-meter and 100-meter world record data (Figures 2 and 4), would sharply reduce those times at ages 91 and 93 . As well, female swimmer F17, if included in the 100-meter and 1500-meter world record data (Figures 5 and 7), would reduce those times at ages $86,87,88,89$, and 90 . The swimmers who bettered the world records posted their times after the Fair ${ }^{7}$ data were collected - as older swimmers continue to participate in Masters programs, the world record data will become more robust at the older ages, and the best times will endure. 
In Fair's analysis of world records ${ }^{7}$ and the analyses of our longitudinal data, only nondominated times were used, so that they could only increase with age. The nondominated times represented about half the times recorded in both the world record data and our longitudinal data, leaving age gaps as shown in Figures 2-7. As swimmers of all ages continue to participate in the Masters program, the world record data will become more robust at older ages and nondominated data will emerge at younger ages, strengthening the data set across the entire age span and allowing a more accurate determination of the transition ages between linear and quadratic performance declines for men and women, in both sprint and endurance events.

Multiple factors determine swimming speed and its decline with aging, including physiological factors such as the energy cost of swimming and maximal metabolic power available, which increase and decrease, respectively, with age. Physical factors, such as stroke mechanics and hydrodynamic resistance, also play a role, with hydrodynamic resistance, at least for the front crawl (freestyle) stroke, increasing at the slower speeds of older swimmers. ${ }^{4,5}$ The relative contributions of these factors to age-related performance decline in Masters swimmers are not fully known and require further study.

Because of the shallower rates of decline noted in most of the swimmers relative to Fair's world record data, we infer a practice effect that partially mitigated the decline in physiological functional capacity with age. There are multiple components of such an effect, including improved physiological function (increased muscle mass, increased vital capacity, improved body flexibility), improved technique (stroke mechanics/efficiency, diving, turns, pacing throughout an event), and external factors (improvements in swim suit, equipment, and pool design). We acknowledge that Masters athletes are not representative of the general population, in that they may have a genetic advantage for physical performance (often in size and body type); they usually have pursued rigorous training schedules for years in the face of conflicting life events; and when injured, they may abruptly lose their elite abilities. They are, however, the best representations of the limits of human performance and endurance in their sport.

Although the age-related decline in the physical performance of essentially all activities, including competitive Masters swimming, is inevitable, the longitudinal data presented herein support what is seen in practice - the ability of individuals to participate in high-intensity swimming over several decades, competitively improving over those decades until, in some instances, they become world record holders for their age groups.

\section{Acknowledgments}

We thank the following individuals who generously contributed to this study: Walt Reid, US Masters Swimming Records Administrator, organized and provided the longitudinal swimming data; Ray C Fair PhD performed regression analyses on the longitudinal data, provided world record data for inclusion in Table 1 and the Figures, and commented on manuscript revisions; Evelyn Ford provided expert assistance with data analysis and Figure preparation.

\section{Author contributions}

Robert Rubin conceived the study, oversaw data collection and organization, assisted in data analyses, prepared the first draft and revisions of the manuscript, and is the corresponding author. Sonia Lin, Amy Curtis, and Charlene Win were primarily responsible for data collection and organization, and participated in manuscript revision. Daniel Auerbach participated in data organization, assisted in preparation of the Figures, and participated in manuscript revision.

\section{Disclosure}

SL and AC were supported by the American Pediatric Society and the Society for Pediatric Research Student Research Program. The authors report no conflicts of interest in this work.

\section{References}

1. Wiswell RA, Hawkins SA, Jaque SV, et al. Relationship between physiological loss, performance decrement, and age in master athletes. J Gerontol A Biol Sci Med Sci. 2001;56(10):M618-M626.

2. Arthur RJ. Swimming and cardiovascular fitness in the older age group. J Sports Med. 1975;3(1):35-39.

3. Rubin RT, Rahe RH. Effects of aging in Masters swimmers: 40-year review and suggestions for optimal health benefits. Open Access $J$ Sports Med. 2010;1:39-44.

4. Zamparo P, Gatta G, di Prampero P. The determinants of performance in master swimmers: an analysis of master world records. Eur J Appl Physiol. 2012;112(10):3511-3518.

5. Zamparo P, Dall'Ora A, Toneatto A, Cortesi M, Gatta G. The determinants of performance in master swimmers: a cross-sectional study on the age-related changes in propelling efficiency, hydrodynamic position and energy cost of front crawl. Eur J Appl Physiol. 2012;112(12): 3949-3957.

6. Donato AJ, Tench K, Glueck DH, Seals DR, Eskurza I, Tanaka H. Declines in physiological functional capacity with age: a longitudinal study in peak swimming performance. J Appl Physiol. 2003;94(2): 764-769.

7. Fair RC. Estimated age effects in athletic events and chess. Exp Aging Res. 2007;33(1):37-57.

8. US Masters Swimming National Records [webpage on the Internet] United States Masters Swimming, Inc; 2013. Available from: http:// www.usms.org/comp/usmsrecords.php. Accessed January 28, 2013. 
9. Honorees/Awards [webpage on the Internet]. Fort Lauderdale, FL: International Swimming Hall of Fame; 2012. Available from: http:// www.ishof.org/awards/INTLMASTERS.html. Accessed January 28, 2013.

10. Tanaka H, Seals DR. Age and gender interactions in physiological functional capacity: insight from swimming performance. J Appl Physiol. 1997;82(3):846-851.

11. Fair RC. How fast do old men slow down? Rev Econ Stat. 1994;76(1): 103-118.

12. Martin JC, Farrar RP, Wagner BM, Spirduso WW. Maximal power across the lifespan. J Gerontol A Biol Sci Med Sci. 2000;55(6):M311-M316.

13. Tanaka H, Seals DR. Dynamic exercise performance in Masters athletes: insight into the effects of primary human aging on physiological functional capacity. J Appl Physiol. 2003;95(5):2152-2162.

14. Bieuzen F, Hausswirth C, Louis J, Brisswalter J. Age-related changes in neuromuscular function and performance following a high-intensity intermittent task in endurance-trained men. Gerontology. 2010;56(1): $66-72$.
15. Fujimoto N, Prasad A, Hastings JL, et al. Cardiovascular effects of 1 year of progressive and vigorous exercise training in previously sedentary individuals older than 65 years of age. Circulation. 2010;122(18): 1797-1805.

16. Nakamura E, Miyao K. Sex differences in human biological aging. J Gerontol A Biol Sci Med Sci. 2008;63(9):936-944.

17. American College of Sports Medicine; Chodzko-Zajko WJ, Proctor DN, Fiatarone Singh MA, et al. American College of Sports Medicine position stand. Exercise and physical activity for older adults. Med Sci Sports Exerc. 2009;41(7):1510-1530.

18. Pollock ML, Mengelkoch LJ, Graves JE, et al. Twenty-year follow-up of aerobic power and body composition of older track athletes. $\mathrm{J} \mathrm{Appl}$ Physiol. 1997;82(5):1508-1516.

19. Davison R. The ageing cyclist. In: Hopker J, Jobson S, editors. Performance Cycling: the Science of Success. London: Bloomsbury; 2012:232-241.

\section{Publish your work in this journal}

Open Access Journal of Sports Medicine is an international, peer-reviewed, open access journal publishing original research, reports, reviews and commentaries on all areas of sports medicine. The manuscript management system is completely online and includes a very quick and fair peer-review system.
Visit http://www.dovepress.com/testimonials.php to read real quotes from published authors. 